\title{
Apomorphine-induced pecking in pigeons classically conditioned to environmental cues
}

\author{
U. Lindenblatt and J.D. Delius* \\ Experimentelle Tierpsychologie, Psychologisches Institut, Ruhr-Universität, D-4630 Bochum, Federal Republic of Germany
}

\begin{abstract}
The dopamine agonist apomorphine elicits protracted pecking when injected systemically $(1 \mathrm{mg} / \mathrm{kg})$ into pigeons. In two experiments it was investigated whether apomorphine would function as an unconditioned stimulus in the classical conditioning of pecking in these animals. An experimental design based on a differentiation procedure was used so that possible pseudoconditioning effects were controlled. Two differently coloured test chambers served as negative (CS -) and positive conditioned (CS +) stimuli. During the training phase the subjects experienced the former while injected with saline, and the latter while injected with apomorphine. In later tests not involving any injections the pigeons made significantly more pecks (conditioned response) in the $\mathrm{CS}+$ chamber than in the $\mathrm{CS}-$ chamber. In the first and second experiments the conditioned stimuli were, respectively, discrete and diffuse visual cues, but both had similar effects. The conditioning obtained may explain sensitization effects that are observed with repeated apomorphine injections. Apomorphine probably also functions as a positive reinforcer for instrumental conditioning in pigeons.
\end{abstract}

Key words: Dopamine agonist - Apomorphine - Pavlovian conditioning - Pecking - Pigeons

From the point of view of learning theory every drug that yields a reliable behavioural effect is potentially an effective unconditioned stimulus in the context of classical (Pavlovian) conditioning. Indeed many studies have demonstrated that vegetative behavioural responses induced by a variety of drugs can be associated to initially neutral stimuli (Davey 1981; Siegel 1982). Fewer studies have shown that somatic behavioural responses triggered by drugs can also be conditioned. Most of these latter studies have been concerned with locomotor activity (e.g. Tilson and Rech 1973; Carey 1986); more specific somatic responses such as grooming, sniffing, staring (Ellinwood 1971) seem to have received less attention.

Apomorphine, a potent dopamine agonist, has long been known to elicit protracted pecking (Amsler 1923; Brunelli et al. 1975; Machlis 1980). Pigeons will begin to

* Present address: Allgemeine Psychologie, FG Psychologie, Universität Konstanz, D-7750 Konstanz, Federal Republic of Germany

Offprint requests to: J.D. Delius

Konstanzer Online-Publikations-System (KOPS)

URL: http://nbn-resolving.de/urn:nbn:de:bsz:352-203039 peck within a few minutes after an intramuscular (IM) injection of an optimally effective dose of about $1 \mathrm{mg} / \mathrm{kg}$ apomorphine, continue for nearly $90 \mathrm{~min}$, reaching a maximum rate of about 10 responses/min some $10 \mathrm{~min}$ after injection, pecking altogether some 5000 times. In comparable circumstances, control, saline-injected pigeons on average peck less than once (Delius 1985). Even though the birds do not normally swallow grain during these drug-induced fits (apomorphine actually has an anorexic effect: Deviche 1984), the pecking exhibited is closely similar to that shown during feeding. If small contrasting visual stimuli are offered in the testing environment the pecks tend to be directed at these; the targets also augment the frequency of pecking (Brunelli et al. 1975; Basten-Kreft 1977). Pigeons will, however, also exhibit apomorphine-induced pecking in absolute darkness (own observations).

Incidental observations by one of us (Lindenblatt 1986) suggested that pigeons that had experienced an apomorphine-induced pecking fit in a particular environment would, when placed back into it several days later without having been given any drug, begin to peck spontaneously. The possibility that this pecking might represent a conditioned response (CR) was investigated in formal experiments that we now describe.

\section{Materials and methods}

A Pavlovian stimulus differentiation paradigm that can distinguish proper conditioning from pseudoconditioning was employed (Davey 1981). Eighteen adult homing pigeons (Columba livia) of local stock weighing between 450 and $550 \mathrm{~g}$ were used for the first experiment. They were experimentally naive and were normally kept in individual cages with food and water freely available in a well ventilated and brightly lit animal room. The birds were divided at random into two groups of nine. The members of group A were injected IM with $0.05 \mathrm{ml}$ saline as an indifferent stimulus (IS) on day 1 of the experiment and placed into an experimental cage $(45 \times 40 \times 35 \mathrm{~cm})$ that had three sidewalls and the ceiling lined with white cardboard peppered with green dots ( $8 \mathrm{~mm}$ diameter, 10 dots per sq.dm; negative conditioning stimulus CS - ) for $60 \mathrm{~min}$. Immediately afterwards they were injected IM with $1 \mathrm{mg} / \mathrm{kg}$ apomorphine in $0.5 \mathrm{ml}$ saline (as an unconditioned stimulus US) and placed in another, adjacent experimental cage whose walls and ceiling were similarly furnished with black cardboard and yellow dots, (size and density as before). They 
Table 1. Conditioned pecking of apomorphine-treated pigeons. Pecks per $10 \mathrm{~min}$

\begin{tabular}{|c|c|c|c|c|c|c|c|c|c|c|c|c|c|c|c|c|c|c|}
\hline \multirow{3}{*}{$\begin{array}{l}\text { Conditioning } \\
\text { Testing } \\
\text { Pigeons }\end{array}$} & \multicolumn{8}{|c|}{$\begin{array}{l}\mathrm{CS}^{+} \text {black/yellow/US apomorphine } \\
\mathrm{CS}^{-} \text {white/green/IS saline }\end{array}$} & \multicolumn{10}{|c|}{$\begin{array}{l}\mathrm{CS}^{+} \text {white/green/US apomorphine } \\
\mathrm{CS}^{-} \text {black/yellow/IS saline }\end{array}$} \\
\hline & \multicolumn{4}{|c|}{$\mathrm{CS}^{+} \rightarrow \mathrm{CS}^{-}$} & \multicolumn{4}{|c|}{$\mathrm{CS}^{-} \rightarrow \mathrm{CS}^{+}$} & \multicolumn{5}{|c|}{$\mathrm{CS}^{+} \rightarrow \mathrm{CS}^{-}$} & \multicolumn{5}{|c|}{$\mathrm{CS}^{-} \rightarrow \mathrm{CS}^{+}$} \\
\hline & A & B & $\mathrm{C}$ & $\mathrm{D}$ & $\mathrm{E}$ & $\mathrm{F}$ & $\mathrm{G}$ & $\mathrm{H}$ & $\mathrm{I}^{\mathrm{a}}$ & $\mathrm{J}$ & $\mathrm{K}$ & $\mathrm{L}$ & M & $\mathrm{N}^{\mathrm{a}}$ & $\mathrm{O}$ & $\mathrm{P}$ & $Q$ & $\mathbf{R}$ \\
\hline $\mathrm{CR}^{+}$ & 17 & 16 & 12 & 18 & 57 & 11 & 42 & 22 & 0 & 71 & 42 & 257 & 20 & 0 & 57 & 11 & 42 & 22 \\
\hline $\mathrm{CR}^{-}$ & 4 & 0 & 0 & 0 & 1 & 0 & 0 & 0 & 0 & 0 & 10 & 0 & 0 & 0 & 1 & 0 & 0 & 0 \\
\hline
\end{tabular}

${ }^{a}$ As subjects $\mathrm{I}$ and $\mathrm{N}$ did not respond in either testing condition replicate subjects $\mathrm{J}$ and $\mathrm{O}$ were run

were left in this positive conditioning stimulus $(\mathrm{CS}+)$ for $60 \mathrm{~min}$. The pigeons of group B were treated the same way, except that they were placed in the black/yellow cage while injected with saline, and the white/green cage while injected with apomorphine. Intermittent observations confirmed that in each subject saline did not lead to any pecking, and that apomorphine yielded a pecking fit as described above. Afterwards the pigeons were returned to their home cages. On days 2 and 3 the treatment were repeated in exactly the same way, that is each pigeon experienced altogether three $\mathrm{CS}-/ \mathrm{IS}$ and three CS +/US pairings.

After a day of rest the critical test session took place on day 5. Without any injections each pigeon was placed back for $10 \mathrm{~min}$ first into one of the experimental cages and then into the other. Within each group of subjects half of the pigeons began with the white/green cage and then finished with the black/yellow cage, the other half of each group experiencing the reverse sequence. An observer who was naive as to which treatments the various pigeons had experienced during training, but who was experienced in scoring pecking elicited by apomorphine, recorded the conditioned responses (CR) in the presence of the CS + and CS - through a one-way screen from an adjacent room.

A second experiment involved eight new pigeons. The same basic design was used except that the experimental cages, instead of being furnished with patterned/coloured walls, were simply illuminated with alternative red or green coloured reflector-lightbulbs $(60 \mathrm{~W})$ placed $2 \mathrm{~m}$ away. On days $1,2,4$, and 5 the pigeons were exposed for $60 \mathrm{~min}$ under saline to one coloured illumination and then under apomorphine for $60 \mathrm{~min}$ to the other. On days 3 and 6 the pigeons were tested untreated for $10 \mathrm{~min}$ in both situations. An observer who was uninformed as to their conditioning treatment scored their pecking responses.

\section{Results}

In the first experiment 16 of the 18 pigeons on average pecked 25.0 times per $10-\mathrm{min}$ test observation period. In detail these latter pigeons emitted 48.9 pecks $/ 10 \mathrm{~min}(\mathrm{CR}+)$ in the $\mathrm{CS}+$ chamber, which during training they had experienced while injected with apomorphine, and only 1.1 pecks $/ 10$ min $(C R-)$ in the $C S$ - chamber where they had been previously placed after saline injections. Table 1 shows that in the test condition (no US or IS) all these 16 pigeons issued more $\mathrm{CR}$ pecks in the $\mathrm{CS}+$ cage than in the CS - cage. Two pigeons did not peck in either situa- tion (overall: Wilcoxon test, $P<0.01$ ). The advantage of the CS + operated independently whether the white/green or the black/yellow cage was the relevant cage, even though the former was somewhat more effective in triggering pecking than the latter $(73.4 \mathrm{CR}+$ and $1.6 \mathrm{CR}$ - pecks as compared with $24.4 \mathrm{CR}+$ and $0.6 \mathrm{CR}-$ pecks). Most conditioned pecks in both the CS + and CS-- were directed at the spotted walls, a few $(16.4 \%)$ were directed at the cage floor, their own toes or at their own plumage. When considered separately this latter pecking also seemed to be under $\mathrm{CS}+$ control $(93.6 \%$ pecks in the presence of the $\mathrm{CS}+)$.

The latter finding suggested some of the conditioning was to a diffuse stimulus context rather than just the discrete stimuli at which pecking was directed. This motivated the second experiment using diffuse coloured light as CS. During tests on day 3 of that experiment the pigeons made an average of 11.7 pecks/ $10 \mathrm{~min}$ in the $\mathrm{CS}+$ condition and 1.9 pecks/10 min in the CS - condition. On day 6 the corresponding figures were 17.9 and 9.8 pecks (Wilcoxon tests, respectively, $P<0.01$ and $P<0.05$ ). Thus a diffuse stimulus context was an effective CS, although not as potent as the more discrete target stimuli used in the first experiment (Mann-Whitney tests, $P<0.05$ ). There is also a cumulative effect with increasing number of conditioning trials, as the overall pecking increased significantly from day 3 to day 6 (Wilcoxon test, $P<0.05$ ) even though, presumably due to greater generalization (increased responding also in the CS - situation), the discrimination performance did not improve.

\section{Discussion}

The results establish that systemically administered apomorphine can function as a Pavlovian US with visual cues as CS, pecking being both the UR and the CR. The effectiveness of certain drugs as excitatory US for vegetative responses was already noted by Pavlov (1927). He describes an experiment in which a dog was repeatedly injected with morphine, each injection eliciting among other responses copious salivation. After several such injections, it was observed that even the preparations preceding injection elicited morphine-like effects, including salivation. Siegel (1982) mentions further examples and also reviews a number of instances where tolerance and other compensatory responses to drugs conditioned to external stimuli. It has similarly been demonstrated that drugs can function as inhibitory US in conditioned toxicosis experiments. Ani- 
mals and humans learn to avoid food previously associated with nausea produced by drugs, including high doses of apomorphine (Garcia et al. 1966; Davey 1981). Regarding non-vegetative behavioural respones Tilson and Rech (1973) demonstrated that in rats the increased locomotory activity caused by amphetamine administration conditioned to the injection/test context. Carey (1986) has further shown that circling locomotion induced by either amphetamine or apomorphine in substantia nigra-lesioned rats conditioned to novel environments. It has not often been demonstrated, though, that a drug can function as an excitatory US for more specific somatic responses. Ellinwood (1971) reported that methamphetamine-induced staring, sniffing and grooming conditioned to the test environment in cats. The conditioning of apomorphine-elicited pecking to visual stimuli that we report is a striking further example.

We suspect that at least part of the sensitization, an increase in response, that has been reported to arise with successive administrations of apomorphine (Costentin et al. 1975; Basten-Kreft 1977; Delius 1985) may be due to a conditioning effect. Added to the direct response due to the drug, the response to later injections could also include a CR induced by adventitious CS. If so, the sensitization effect should be at least partly dependent on the constancy of the environment in which the repeated injections took place.

Stimuli that act as excitatory US in classical conditioning are frequently also effective as rewards in instrumental conditioning. It has been already shown that rats will work for intravenous apomorphine injections as reinforcement (Baxter et al. 1974). In preliminary experiments we have recently obtained evidence that pigeons will actively seek locations at which they have been previously experienced apomorphine pecking fits.

Acknowledgements. This research was supported by a grant of the Graduiertenförderung (NRW) to $U$. Lindenblatt and by the Deutsche Forschungsgemeinschaft through its Sonderforschungsbereich 114. We thank Christian Haase and Monika Remy for assisting as "blind" observers, Dagmar Hagenkötter for help with the manuscript and Mary Holzhäuer for bibliographic assistance. We are also grateful to Drs. Trevor Robbins, Clive Wynne and John Staddon for commenting on a draft.

\section{References}

Amsler C (1923) Beiträge zur Pharmakologie des Gehirns. Arch Exp Pathol Pharmakol 97:1-27

Basten-Kreft A (1977) Apomorphin-induziertes Verhalten bei Tauben. Diplomarbeit, Ruhr-Universität, Bochum

Baxter BL, Gluckman MI, Stein L, Scerni RA (1974) Self-injection of apomorphine in the rat: positive reinforcement by a dopamine receptor stimulant. Pharmacol Biochem Behav 2:387-392

Brunelli M, Magni F, Moruzzi G, Musumeci D (1975) Apomorphine pecking in the pigeon. Arch Ital Biol 113:303-325

Carey RJ (1986) Conditioned rotational behavior in rats with unilateral 6-hydroxydopamine lesions of the substantia nigra. Brain Res 365:379-382

Costentin J, Protais P, Schwartz JC (1975) Rapid and dissociated changes in sensitivities of different receptors in mouse brain. Nature 257:405-407

Davey G (1981) Animal learning and conditioning. Macmillan, London

Delius JD (1985) The peck of the pigeon: free for all. In: Lowe CF, Richelle M, Blackman DE, Bradshaw CM (eds) Behaviour analysis and contemporary psychology. Erlbaum, New York, pp 53-81

Deviche P (1984) Administration of small doses of apomorphine attenuates feeding in non-deprived pigeons. Physiol Behav 33: $581-585$

Ellinwood EH (1971) "Accidental conditioning" with chronic methamphetamine intoxication: implications for a theory of drug habituation. Psychopharmacology $21: 131-138$

Garcia J, Ervin FR, Koelling RA (1966) Learning with long delay of reinforcement. Psychon Sci 5:121-123

Lindenblatt U (1986) Die dopaminerge Auslösung des Pickverhaltens bei Tauben. Dissertation, Ruhr-Universität, Bochum

Machlis L (1980) Apomorphine: effects on the timing and sequencing of pecking behavior in chicks. Pharmacol Biochem Behav 13:331-336

Pavlov IP (1927) Conditioned reflexes (G.V. Anrep. transl.) Oxford University Press, London

Siegel S (1982) Pharmacological habituation and learning. In: Commons ML, Herrnstein RI, Wagner AR (eds) Quantitative analyses of behavior III: Acquisition. Ballinger, Cambridge, Massachusetts, pp 195-217

Tilson HA, Rech H (1973) Conditioned drug effects and absence of tolerance to d-apomorphine induced motor activity. Pharmacol Biochem Behav 1:149-153 